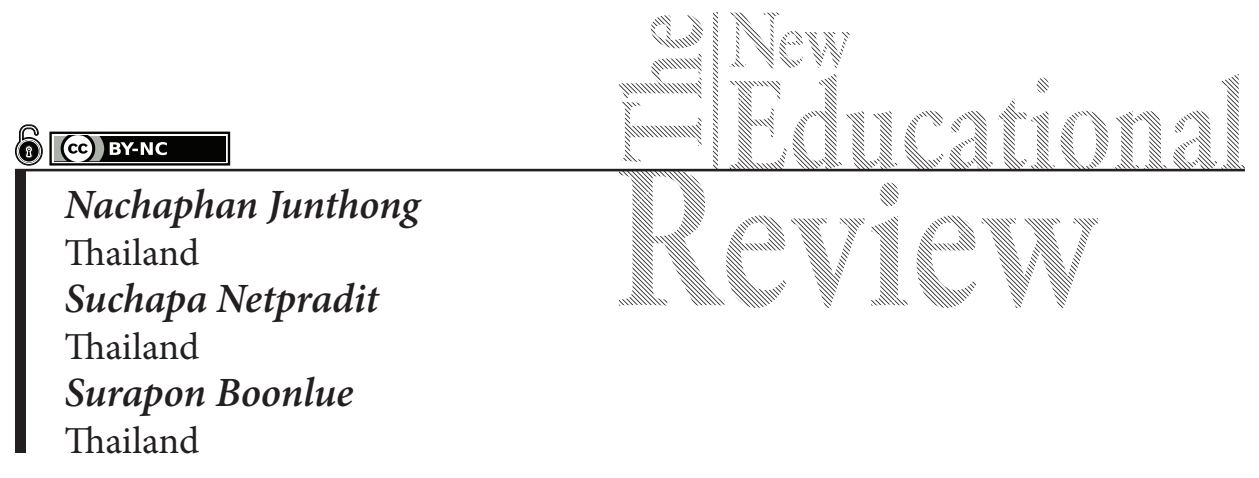

\title{
The Designation of Geometry Teaching Tools for Visually-Impaired Students Using Plastic Geoboards Created by 3D Printing
}

DOI: 10.15804/tner.2020.59.1.07

\begin{abstract}
In the present study, plastic geoboards and accessories were created as geometry teaching tools for visually-impaired students, using 3D printing. Lines, shapes, and angles were illustrated by stretching rubber bands around rivet heads on a geoboard with square edge of $10 \times 10$ grid array and circular edge of 4-quadrant graph. The coordinate points of $2 \mathrm{D}$ geometry were explored by blind touch on braille scales and raised grid lines, while z-axis pillars were used for $3 \mathrm{D}$ geometry by connecting rubber bands to the plane. The experimental group revealed significantly more learning achievement than did the control group, and all participants agreed that the new geoboards enhanced the mental imagery and understanding of geometry.
\end{abstract}

Keywords: geometry, geoboard, teaching tool, 3D printing, visually-impaired students

\section{Introduction}

Geometry is one area of mathematics for teaching about lines, line segments, rays, angles and geometric shapes. The contents are developed to learn how to measure lengths of lines, angles, perimeters and areas of $2 \mathrm{D}$ shapes. The volumes and surface areas of 3D shapes can be calculated using geometry concepts. Almost 
all geometry problems require a drawing which cannot be used on a Braille typewriter. Zahra, Budayasa, \& Juniati (2018) interviewed blind students about their interpretation of two-dimensional shapes according to their thinking. They explained that "the visual experience of a blind student with total blindness from birth has an important role in the way s/he illustrates or describes a two dimensional shape. The shape and the length of the subject line is explored by using tactual ability through its sense of touch". Jurmang (2015) found that the new adapted teaching strategy developed applied orientation and mobility programme gave access to learners with visual impairment to participate in geometry and it enhanced task performance of the learners in geometry. Sibiya \& Mudaly (2018) investigated the effects of the Geoboard on learners' understanding of geometric theorems in two secondary schools. The results revealed that Geoboards improved learners' understanding of geometric theorems, especially understanding geometric terminology and reasoning.

Recently, geoboards have become popular effective tools for teaching geometry to visually-impaired students. Geoboards can benefit teachers and students by helping to capture their explanation of a geometric concept for discovery or illustration by students with visual-impairments, low vision and normal vision. There are several teaching tools available on the market that can serve this purpose effectively; however, the imported products are too expensive. Therefore, teachers need to implement certain techniques to provide visually-impaired students with an effective math education by using braille cards. Mathematics' teachers in schools for the blind always need geometry teaching tools for students who are blind or visually impaired.

In our previous work (Junthong, Netpradit, \& Boonlue, 2017), the requirements of teachers and visually-impaired students in mathematics classes of many schools for the blind were obtained using semi-structured interviews. The information revealed that the most difficult content was geometry and that the teaching tools were not sufficiently effective for visually-impaired students in elementary classes. The braille books were not good enough for the students' understanding because students need real materials/objects to improve their visual imagery. All visually-impaired students also need 3D models to help them with their blind touch following the teachers' instruction, in order to enhance their learning, especially for geometry. The researchers found that the old wooden geoboards in the mathematics classes at the Bangkok School for the Blind were large, heavy, colorless and hard to use. There were carved grid lines on a plane with square edges and circular edges which were designed by Chaiyadech (2011), as shown in Fig. 1. According to 
the difficulty of wooden geoboard making and carrying, we propose to replace the existing model with the unlimited design of light and colorful geoboards.
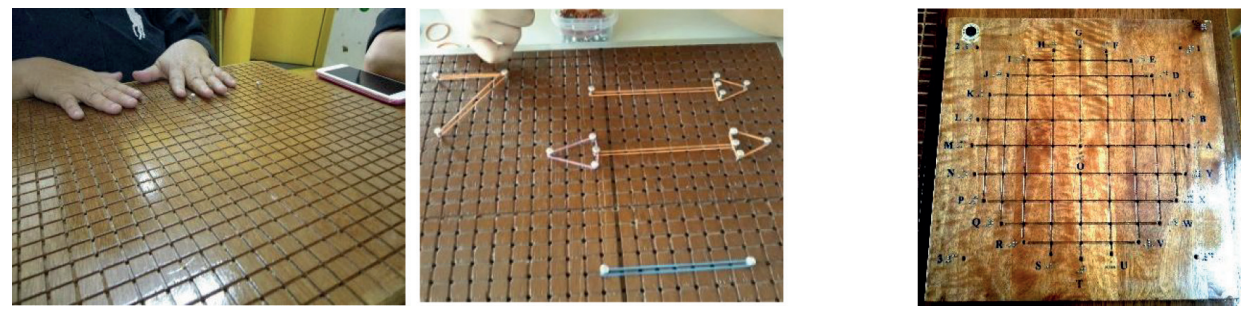

Figure 1. The traditional wooden geoboard with square edges and Chaiyadech's geoboard with circular edges

Recently, 3D printing technology is one of the most advantageous technologies for inventions, when compared to the traditional manufacturing methods (Tractus3D, 2019) because of the high level of accuracy and the ability to make decisions which reduce cost, time, and errors. Loconsole, Leonardis, Bergamasco, and Frisoli (2016) investigated how Braille characters can be produced through the upcoming 3D printing technology and explained that "the printing algorithm and printer parameters can be modified and optimized for Braille". Visually-impaired volunteers evaluated the different printing approaches in terms of readability and comfort in reading. The optimal dimensions of braille dots for readability and raised lines for easy exploring by the sense of touch were tested with fourth-grade visually-impaired students (Junthong, Netpradit, \& Boonlue, 2018). We found that the appropriate dot height of each braille cell for $3 \mathrm{D}$ printing should be increased to $1.5 \mathrm{~mm}$, however the dot cell diameter was $1.5 \mathrm{~mm}$ as with standard braille (Loconsole, et al., 2016). Implementation has also been tested by the teachers of mathematics in a school for the blind. Therefore, the researchers produced new teaching/learning materials by creating a set of geoboards developed as per the users' requirement by using $3 \mathrm{D}$ printing, in which the material was joined or solidified under computer control, in order to create a three-dimensional model. The properties of the geoboard models were sometimes adjusted to be optimized for the users' requirements.

\section{Research Questions}

In this study, the researchers created and produced new geoboards with a square edge and circular edge for teaching about line segments, shape areas, angles, circle components, and 3D geometric shapes; cube, pyramid, prism, etc. Colorful porta- 
ble effective geoboards were mainly designed for low-vision and visually-impaired students in an elementary classroom at the Bangkok School for the Blind, Thailand. New teaching tools, including plastic geoboard, arrowheads, pillars and 3D object models, were created so that the students could learn about geometry, 2D and $3 \mathrm{D}$ shapes with mental imagery ability improvement. The learning achievement was evaluated for the experimental group that studied using the new geoboard sets compared with the control group that studied using traditional tools. The perspectives of the students regarding their use of the new geoboard sets were observed. Therefore, the specific research questions were as follows:

1. Could the new plastic geoboards and other accessories be applicable to teach and learn for 2D and 3D geometry contents?

2. Does use of the new plastic geoboards improve the learning achievement in geometry with mental imagery abilities of visually-impaired students?

3. Do the new plastic geoboards satisfy the teachers and students in the mathematics class who were the participants in this study?

\section{Methodology of Research}

\section{Instruments}

The new geoboards were created with several patterns and colors for prototype testing using 3D software (SketchUp) and 3D printer (Flashforge Creator Pro). The plastic geoboards were designed to form solid objects under computer control using data from 3D modeling and design programs which were drafted and set up before being exported to a STL file format. The model drafting for the geoboard with a grid array in a square shape and with a circular shape was then printed by adding layers of Polylactic acid (PLA) filament that is molten within the printing nozzle, which extruded on the underneath printed layer, and cools down to ambient temperature. The eco-friendly PLA filament was provided in a roll which is commercially distributed for below 30 USD. A colored geoboard was produced in 18 hours with half a roll using a small-size Flashforge Creator Pro 3D printer, as shown in Fig. 2.

The colorful materials were created to enhance the learning activities for the teachers, the low-vision students, and the visually-impaired students. The portable plastic geoboards were produced in an optimal size of $20 \times 20 \mathrm{~cm}$, with a thickness of $1.4 \mathrm{~cm}$, for exploring and being held by children. There were two patterns: a $10 \times 10$ grid on $\mathrm{x}$-axis and $\mathrm{y}$-axis with a square edge and a 4-quadrant graph with a circular edge with 24 circumference scales. Each coordinate point 

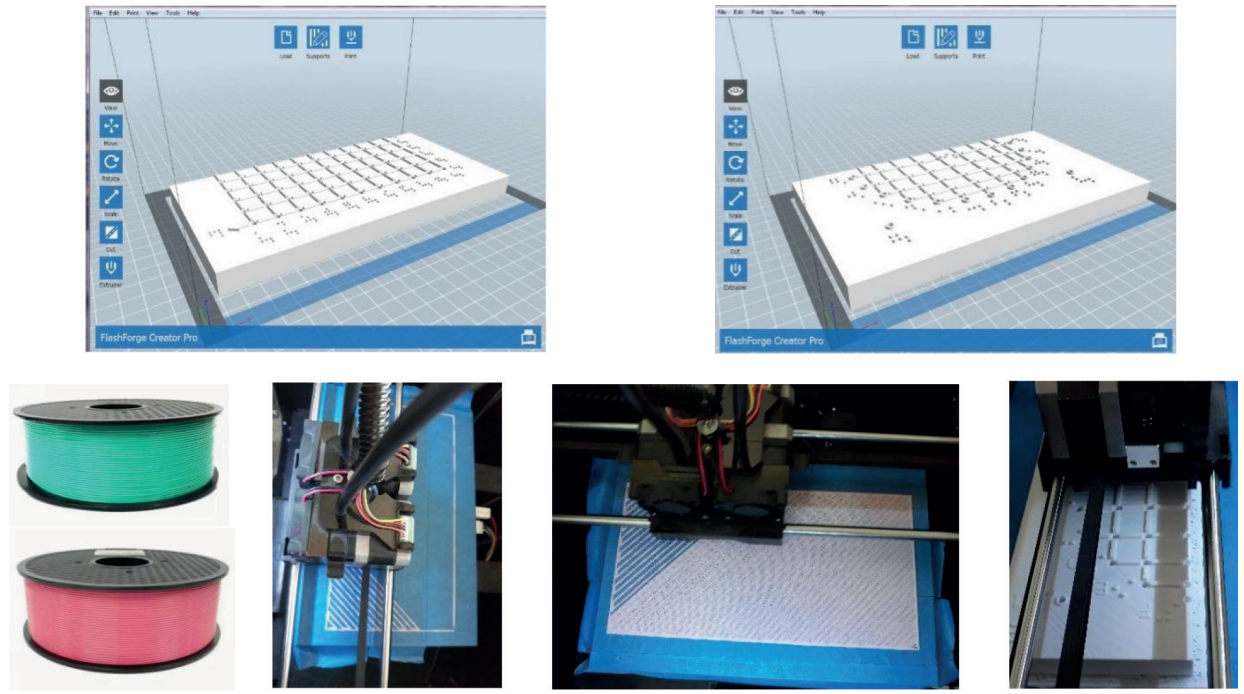

Figure 2. The model of geoboards by drafting with the SketchUp 3D software and application of $3 \mathrm{D}$ printer in producing the PLA plastic geoboards

had a hole of $3.75 \mathrm{~mm}$ in diameter and $1.4 \mathrm{~cm}$ in depth for sticking half of rivets. In order to be used with visually-impaired students, there are braille scales to identify 0 to 10 on the $x$-axis and y-axis, and raised dots with two columns of three dots at the top-right corner as a symbol for the upright position. Z-axis pillars with different heights, identified by braille, were also created for $3 \mathrm{D}$ geometry teaching. On the circular edge, there were 4 quadrants identified by Arabic numbers and braille on the 4 corners. There were 24 points identified by the letters $\mathrm{A}$ to $\mathrm{Y}$ on the circumference with a 15-degree angle difference for teaching about circles and tangents. The central point was identified by the letter $\mathrm{O}$ and the circle diameter was $13 \mathrm{~cm}$. Raised grid lines $1.5 \mathrm{~mm}$ in height were also generated for exploring direction by blind touch. The teaching tool set included other teaching accessories, such as rulers, protractors and arrow heads, as shown in Fig. 3. Solid objects; spheres, cones, cylinders, pyramids and cubes, were made of PLA plastic for teaching about 3D geometry. The teachers could teach the visually-impaired students about the surface areas and volumes of $3 \mathrm{D}$ shapes, as well as the areas and perimeters of $2 \mathrm{D}$ shapes. The $3 \mathrm{D}$ object models could be separated into unit segments for study of the composition and connection of it step by step. 


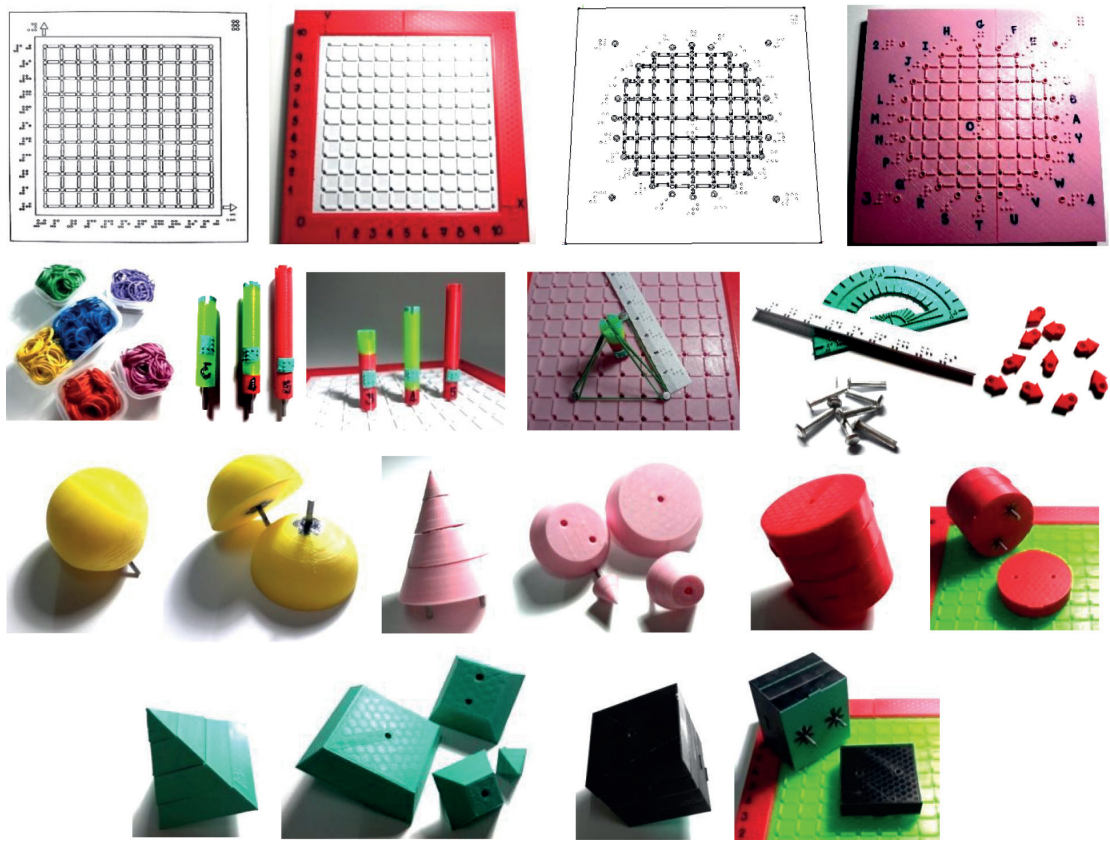

Figure 3. A plastic geoboard with square and circle edges including learning accessories, and the segments of 3D objects for spheres, cones, cylinders, pyramids and cubes

\section{Participants}

The learning achievement regarding geometry between the experimental group and the control group was evaluated by comparing mean scores on pre-test and post-tests. The participants in this study were 3 teachers and 15 students with visual impairment in a $4^{\text {th }}$ grade elementary school class. The students were separated into 2 groups; an experimental group $(n=8)$ and a control group $(n=7)$ which were sampled using random cluster sampling. Three teachers who had experience of at least 7 years provided the information, requirements and suggestions during the process of the geoboard production. All of the students in the experimental group accepted participation in this research by signing an informed consent form, or by allowing a legal representative sign for him or her before the implementation of the study.

\section{Procedures}

There were 15 periods of 1 hour each for different learning activities between the experimental group and the control group. In the first period, all of the students 
had a pre-test using 21 exercises based on the lessons in the book of The Institute for the Promotion of Teaching Science and Technology (2008). The contents for teaching and assessment were limited to the basic scope of geometry lessons for primary education issued by the Ministry of Education in Thailand. The new geoboard set was introduced, presented, and demonstrated to the experimental group during the second period. After that, the experimental group studied using the new plastic geoboards, while the control group used the regular method with the same contents. The post-test was then conducted for both student groups in the classroom after the learning activities in every period. The differences in the mean scores between pre-test and post-test of the two groups were analyzed using independent two-sample t-tests. In order to evaluate their learning achievement, the significant scores were compared between the experimental group and the control group.

In the experiment, the researchers presented the new plastic geoboard and taught basic geometry to the experimental group of visually-impaired students, while the teacher of mathematics in the school taught the same contents to the control group using the regular tools. The contents of the teaching and assessment by post-test with exercises related to the lessons during the 15 periods are shown in Table 1.

Table 1. Contents of teaching and assessment in the experimental group class

\begin{tabular}{llll}
\hline & $\begin{array}{c}\text { Content of } \\
\text { Teaching/As- } \\
\text { sessment }\end{array}$ & $\begin{array}{c}\text { Assessment } \\
\text { methods }\end{array}$ \\
\hline $\begin{array}{l}\text { Knowledge } \\
\text { background of } \\
\text { students }\end{array}$ & $\begin{array}{c}\text { Pre-test with 21 prob- } \\
\text { lems or instructions }\end{array}$ \\
\hline 2 & $\begin{array}{l}\text { Introduction, Tool presentation, and Application of the new geoboard for learning about } \\
\text { geometry }\end{array}$ & $\begin{array}{l}\text { Straight line, } \\
\text { Ray, Line seg- } \\
\text { ment }\end{array}$ & $\begin{array}{l}\text { Post-test: 2 exercises } \\
\text { 1. Draw a straight line. }\end{array}$ \\
\hline 3 & 2. Draw a ray.
\end{tabular}




\begin{tabular}{|c|c|c|c|c|}
\hline 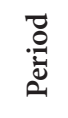 & $\begin{array}{l}\text { Content of } \\
\text { Teaching/As- } \\
\text { sessment }\end{array}$ & $\begin{array}{l}\text { Assessment } \\
\text { methods }\end{array}$ & Tool and Figure & :ँّ \\
\hline $4-5$ & $\begin{array}{l}\text { Angle, Angle } \\
\text { types, Angle } \\
\text { measurement }\end{array}$ & $\begin{array}{l}\text { Post-test: } 3 \text { exercises } \\
\text { From figure: } \\
\text { 3. Where is the vertex of } \\
\text { the angle? } \\
\text { 4. Which angle is } \\
\text { bigger? } \\
\text { 5. Which angle is } \\
\text { smaller? }\end{array}$ & & 3 \\
\hline $6-7$ & $\begin{array}{l}\text { Right angle, } \\
\text { Acute angle, } \\
\text { Obtuse angle }\end{array}$ & $\begin{array}{l}\text { Post-test: } 3 \text { exercises } \\
\text { From figure: } \\
\text { 6. Which one is a right } \\
\text { angle? } \\
\text { 7. Which one is not } \\
\text { a right angle? } \\
\text { 8. Which one is an acute } \\
\text { angle? }\end{array}$ & & 3 \\
\hline $8-9$ & $\begin{array}{l}\text { Several types of } \\
\text { Rectangles }\end{array}$ & $\begin{array}{l}\text { Post-test: } 2 \text { exercises } \\
\text { 9. Identify the types of } \\
\text { angles in a rectangle. } \\
\text { 10. Which one is a rec- } \\
\text { tangle? }\end{array}$ & & 7 \\
\hline $\begin{array}{l}10- \\
11\end{array}$ & $\begin{array}{l}\text { Squares and } \\
\text { Rectangles }\end{array}$ & $\begin{array}{l}\text { Post-test: } 2 \text { exercises } \\
\text { 11. Draw a rectangle. } \\
\text { From figure: } \\
\text { 12. Which one is } \\
\text { a square? }\end{array}$ & & 3 \\
\hline 12 & $\begin{array}{l}\text { Diagonal and } \\
\text { Parallel lines }\end{array}$ & $\begin{array}{l}\text { Post-test: } 2 \text { exercises } \\
\text { From figure: } \\
\text { 13. Which line is a di- } \\
\text { agonal? } \\
\text { 14. Which lines are } \\
\text { parallel? }\end{array}$ & & 3 \\
\hline $\begin{array}{l}13- \\
14\end{array}$ & Circle & $\begin{array}{l}\text { Post-test: } 2 \text { exercises } \\
\text { From figure: } \\
\text { 15. Which line is a ra- } \\
\text { dius? } \\
\text { 16. Which lines are a ra- } \\
\text { dius and diameter? }\end{array}$ & & 4 \\
\hline
\end{tabular}




\begin{tabular}{|c|c|c|c|c|}
\hline : & $\begin{array}{l}\text { Content of } \\
\text { Teaching/As- } \\
\text { sessment }\end{array}$ & $\begin{array}{l}\text { Assessment } \\
\text { methods }\end{array}$ & Tool and Figure & : \\
\hline 15 & $\begin{array}{l}\text { Area of 2D } \\
\text { shapes } \\
\text { Volume of 3D } \\
\text { shapes }\end{array}$ & $\begin{array}{l}\text { Post-test: } 5 \text { exercises } \\
\text { From figure: } \\
\text { 17. Calculate the area of } \\
\text { a rectangle. } \\
\text { 18. Calculate the area of } \\
\text { a square } \\
\text { 19. Find the volume } \\
\text { of cube with a unit } \\
\text { height. } \\
\text { 20. Find the volume of } \\
\text { a cube with a } 2 \text {-unit } \\
\text { height. } \\
\text { 21. Find the volume } \\
\text { of a } 3 \mathrm{D} \text { cube by } \\
\text { stretching rubber } \\
\text { bands round } 4 \text { pil- } \\
\text { lars of } 4 \text { corners. }\end{array}$ & & 5 \\
\hline
\end{tabular}

\section{Data Analysis}

The differences in the mean scores between pre-test and post-test of the two groups were analyzed using independent two-sample t-tests. In order to evaluate their learning achievement, the significant scores were compared between the experimental group and the control group. The quality of the tools and questionnaire were checked by 5 experts: 2 mathematics teachers, 2 chiefs of the Educational Technology for the Blind Center in Thailand, and 1 Director of Primary Mathematics at The Institute for the Promotion of Teaching Science and Technology. The satisfaction level of the teachers and students that had used the new plastic geoboard was then determined using a Likert scale questionnaire. There were 3 main issues for evaluation: the quality of the teaching tools ( 9 items); the benefits of the learning activities ( 4 items); and the properties of real application (11 items). The questionnaire for the students was similar to that of the teachers but there were differences in a few items. There were open-ended questions on the participants' opinions of the tool application, areas for improvement, and other suggestions. The data on the pretest-posttest and satisfaction level were collected after implementation to be analyzed using the SPSS program. 


\section{Results and Discussion of Research}

\section{Application of Teaching Tools for 2D Geometry}

A geoboard with a square edged grid was used to draw a straight line from 2 points and an angle of 2 lines from 3 points on the coordinate plane by stretching rubber bands around the geoboard's rivets, which were half driven into the holes. Arrowheads could be attached to the line ends so that the students could learn geometry concerning straight lines, parallel lines, rays, right angles, acute angles and obtuse angles. The geoboard was also applied for learning about parallel lines and different angles so that the students could compare between right angles, acute angles and obtuse angles, as shown in Fig. 4.
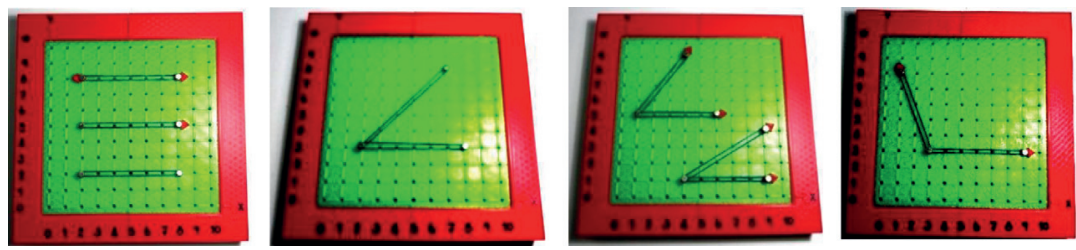

Figure 4. Teaching about straight lines, parallel lines, rays, and angles on a geoboard

The shape of a square, rectangle and any 2D geometric shapes could be drawn from 4 points by stretching rubber bands around the rivet heads, as shown in Fig. 5. Since the distance between the points represented 1 unit (around $1 \mathrm{~cm}$ ), the shape area could be used for teaching students to calculate. To find the area of a rectangle or a square, the students only need to find the length of one of the sides and the width of one of the other sides, and then multiply its height by its width to find the area.
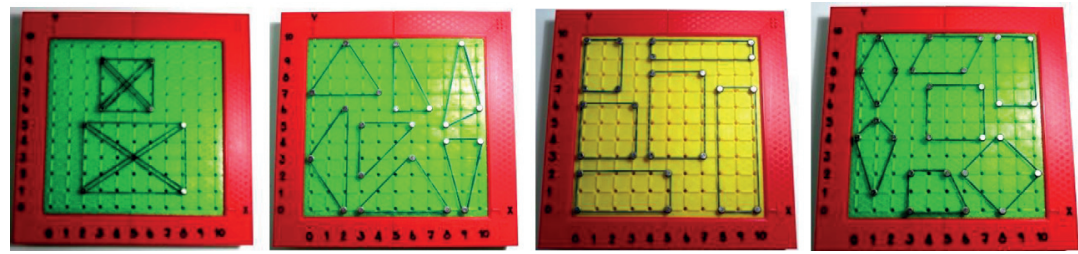

Figure 5. Teaching about 2D shapes, parallelograms and diagonals on a geoboard

The plastic geoboard with a circular shape can be applied for teaching about different angle types such as acute angles, obtuse angles, right angles and also angle 
measurements, or comparisons. The circle and circle components such as diameter, radius, circumference, and tangent can be studied for advanced mathematics. In addition, it can be applied for learning about 2D geometric shapes such as triangles, rectangles, and squares, as shown in Fig. 6.
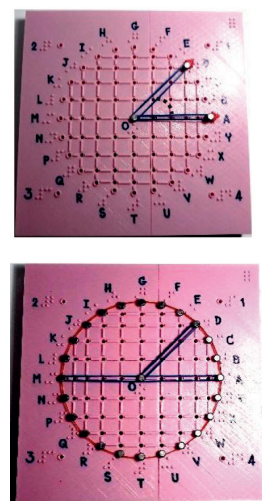
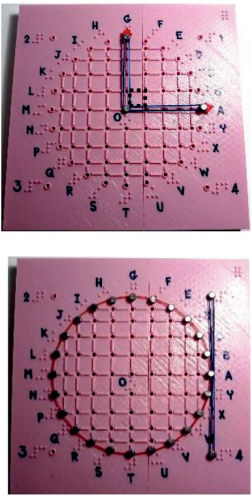
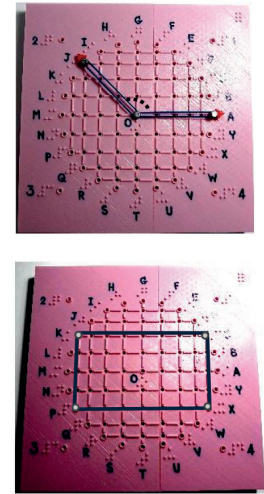
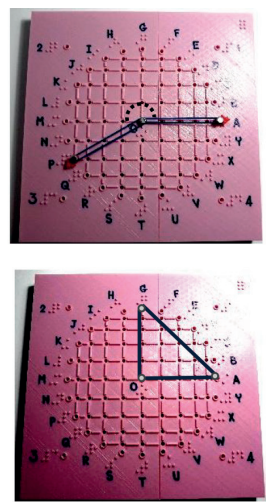

Figure 6. Teaching about angles, circle components, squares and triangles on a geoboard

\section{Application of Teaching Tools for 3D Geometry}

$3 \mathrm{D}$ geometry using the $\mathrm{z}$-axis can be applied on the geoboard by using a plastic pillar to create a pyramid with square base as an object of a pyramid model. A pillar was stabbed down into the center and connected with rubber bands from the plane using 4 rivets, one by one, as shown in Fig. 7. A cube might be effectively created by using 4 pillars with rubber bands stretched around 4 corners to represent an object of a cube model.
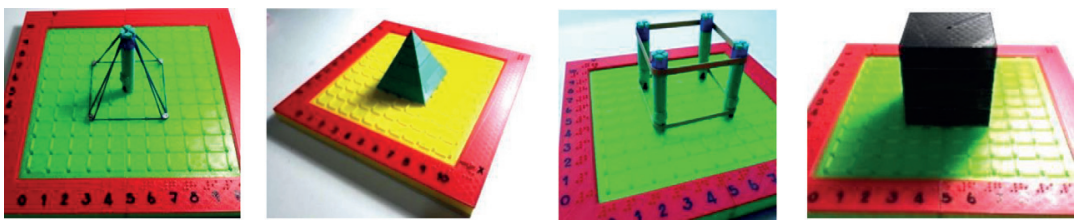

Figure 7. Teaching to create 3D shapes on a geoboard using $\mathrm{z}$-axis pillars, similar to the object models of a pyramid and a cube

For the volume calculation of a cube, the students need to know the length of the square base, which can be explored from the raised grid lines on the geoboard. After the square base area is known, the volume can be found by multiplying it 
by the height. Teachers must advise their students to compose the object model of the cube from one segment (1-unit height) to four segments (4-unit height). The students should learn that the volume of the cube will increase if the height is increased. The volume of $3 \mathrm{D}$ geometric shapes such as cubes, cylinders and pyramids is related to the base area and the factor of the height. The height of the object models from the base can be measured by counting the number of 1-unit segments.

Z-axis pillars with different heights of 4, 5 and 6 units can be used to teach 3D geometric shapes and volumes after the students understand the $3 \mathrm{D}$ object models. A pyramid with a triangular base, a pentagonal base, and a hexagonal base is relatively easy to work with. A prism might be effectively created by using more than one pillar, as shown in Fig. 8. Geometric lines and shapes can be created by either teachers or students, as well as many other items in the geometry syllabus. The raised grid lines with braille numbering are handy for identifying shape locations, measuring distance, and calculating areas or perimeters; and scales can be applied for measuring the diameter or radius of a circle on a cylinder, cone, or sphere and multiplying the area by the height to find the volume.
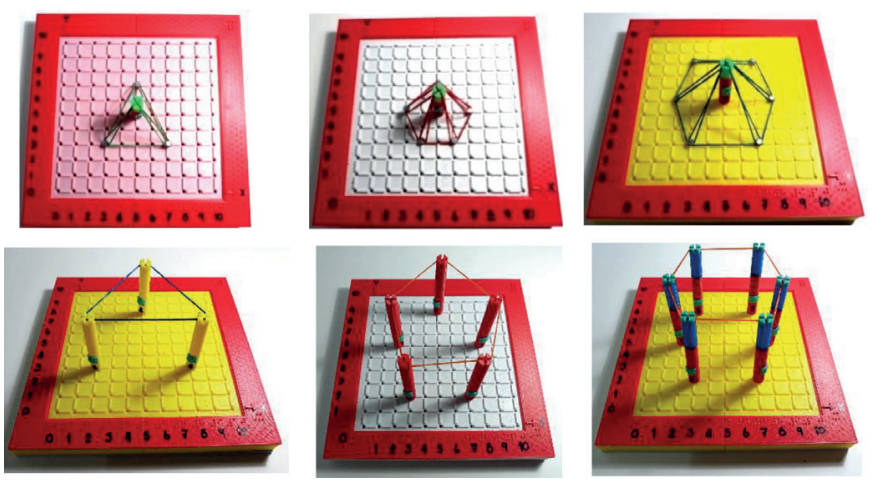

Figure 8. Teaching to create $3 \mathrm{D}$ geometric shapes for pyramids and prisms, similar to the three-dimensional object models on a plastic geoboard

\section{Evaluation of Learning Achievement in Geometry}

An independent $t$-test was used to determine the difference between the mean scores of the pre-test and post-test for the experimental group versus the control group for the related content. The mean scores $(x)$ and standard deviations (SD) for the pre-test and post-test are displayed in Tables 2 and 3. The t-test results 
showed a significant difference for the experimental group $(\mathrm{P}<0.01)$, indicating that the new geoboards were more effective for learning and for the students' understanding than the traditional teaching method. A lower SD of the post-test scores for the experimental group indicates that their scores tend to be close to the mean scores or the expected scores, while a higher SD of the post-test scores for the control group means that some students who learned with the regular method did not understand some contents of geometry.

Table 2. Achievement in learning about geometry using the new plastic geoboard related to the pre-test and post-test for the experimental group

\begin{tabular}{lccccc}
\hline $\begin{array}{l}\text { Experimental } \\
\text { group }(\mathrm{N}=8)\end{array}$ & Full score & $\mathbf{x}$ & SD & t & P \\
\hline Pre-Test & 30 & 7.75 & 2.25 & 50.55 & $.00^{* *}$ \\
\hline Post-Test & 30 & 27.88 & 1.64 & & \\
\hline
\end{tabular}

${ }^{*} \mathrm{P}<0.01$

Table 3. Achievement in learning about geometry using the new plastic geoboard related to the pre-test and post-test for the control group

\begin{tabular}{lccccc}
\hline $\begin{array}{c}\text { Control } \\
\text { group }(\mathrm{N}=7)\end{array}$ & Full score & $\mathbf{x}$ & SD & t & P \\
\cline { 1 - 4 } Pre-Test & 30 & 6.43 & 2.70 & 9.49 & $.00^{\star *}$ \\
\hline Post-Test & 30 & 15.14 & 4.81 & & \\
\hline
\end{tabular}

${ }^{*} \mathrm{P}<0.01$

\section{Evaluation of Participants' Satisfaction}

A questionnaire using a 5-point Likert scale was used to evaluate the satisfaction levels of 3 teachers and 8 students in the Bangkok School for the Blind. The response showed that the new geoboards as a teaching tool were considered to be much more satisfactory than the traditional tool because the mean scores were very high (>4.8) in all areas, as shown in Table 4.

The results show that the tools made the classes more enjoyable for the visually-impaired students and made them enthusiastic about learning with each other. Furthermore, geometry was not thought to be difficult to understand, if the visually-impaired students could generate their mental imagery on any topic using simulation-based learning from tangible objects. The learning activities of the experimental group in the class were observed, as shown in Fig. 9, and it was 
Table 4. The satisfaction level of the teachers and students with the new plastic geoboard compared to the old wooden geoboard

\begin{tabular}{|c|c|c|c|c|c|c|c|c|c|}
\hline \multirow{2}{*}{ Samples } & \multicolumn{3}{|c|}{ Qualities of teaching tools } & \multicolumn{3}{|c|}{$\begin{array}{c}\text { Benefits of learning } \\
\text { activities }\end{array}$} & \multicolumn{3}{|c|}{$\begin{array}{l}\text { Properties of tool } \\
\text { application }\end{array}$} \\
\hline & $\mathrm{X}$ & S.D. & Satisfaction & $\mathrm{X}$ & S.D. & Satisfaction & $\mathrm{X}$ & S.D. & Satisfaction \\
\hline Students & 4.86 & 0.14 & very satisfied & 4.75 & 0.27 & very satisfied & 4.90 & 0.15 & very satisfied \\
\hline Teachers & 4.81 & 0.23 & very satisfied & 5.00 & 0.00 & very satisfied & 5.00 & 0.00 & very satisfied \\
\hline
\end{tabular}

revealed that the students rapidly knew how to apply the new geoboard set in the geometry class. They could draw various geometric shapes according to the teachers' instructions and understand easily the contents of either $2 \mathrm{D}$ or $3 \mathrm{D}$ geometry. In addition, they paid more attention to their learning with enjoyment and showed a good attitude toward using the new plastic geoboard in their class. The teachers and 8 visually-impaired students in the $4^{\text {th }}$ grade agreed that this new geoboard design and accessories were good teaching tools to support their imagery for the learning and understanding of geometric concepts.
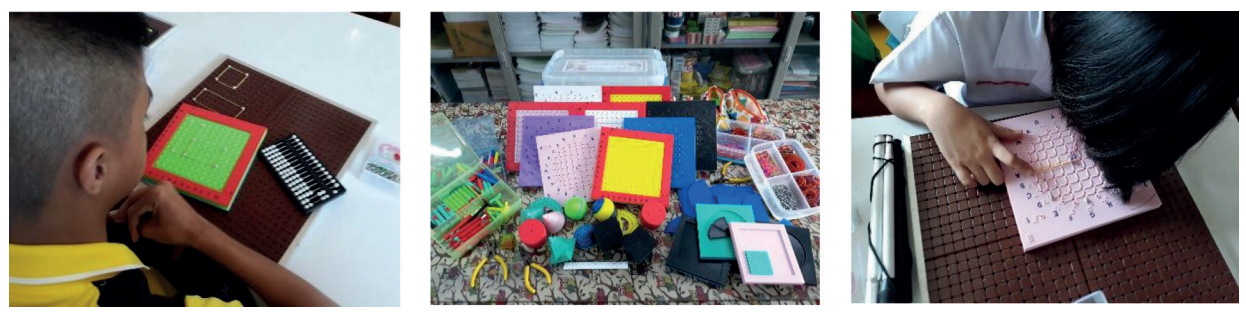

Figure 9. Sets of geoboards and learning accessories for geometry teaching and learning

\section{Conclusions}

The new geometry teaching tools in the present study were designed according to the requirements of the teachers and visually-impaired students in the $4^{\text {th }}$ grade in the Bangkok School for the Blind. The new plastic geoboards, including other accessories for the teaching and learning of geometry, were created and produced from colorful PLA using a 3D printer. They were seen to be effective teaching tools for many topics of geometry, such as lines, rays, angles, and 2D and 3D shapes. The students could learn to draw line segments and two-dimensional shapes on the 
geoboard with rivets and rubber bands. The geoboards can be used to learn about the areas and perimeters of 2D shapes as well as the surface areas and volumes of 3D shapes.

The prototype testing showed that the experimental group had a higher mean score on the post-test than did the control group, indicating that the learning achievement of the visually-impaired students who learn with the new geoboards is significantly higher than that of the students who learn with the regular tools. The participants' satisfaction with the geoboards in terms of learning about geometry was evaluated highly on the part of the teachers and the students because the tangible teaching tools were considered more effective for understanding geometry with good visual imagery than when using the traditional tools. The students enjoyed learning to draw the geometric lines and shapes, and creating the $3 \mathrm{D}$ shapes.

\section{Acknowledgements}

The authors would like to thank the experts at the Foundation for the Blind in Thailand under the royal patronage of Her Majesty the Queen, the Thai National Institute for the Blind for Research and Development, the Institute for the Promotion of Teaching Science and Technology, the Information Technology Service Center for the Blind, the Educational Technology for the Blind Center and the Bangkok School for the Blind.

\section{References}

Chaiyadech, J. (2011). Efficiency of using Geoboard compare with Geometric tactile materials: Case study of fifth grade students with Visual Impairment at school for the blind. M.S. thesis, M.A. (Rehabilitation Science for Persons with Disabilities), Ratchasuda Foundation (college), Mahidol University, Thailand.

Gattegno, Caleb (1971). Geoboard geometry. [S.1.]: Educational Solutions Worldwide Inc., 72.

Jurmang, I. (2015). Effect of Applied Orientation and Mobility Programme on Attitude and Achievement in Geometry of Learners with Visual Impairment in Abuja and Gindiri, doctoral dissertation, University of Jos, Nigeria, xiii.

Junthong, N. Netpradit, S. \& Boonlue, S. (2017). The Study of Status and Needs for Instructional Media of Blind Students from Upper Elementary School in Thailand. Proceedings of $6^{\text {th }}$ International Conference on Education, Humanities and Social Sciences Studies (EHSSS-17), Singapore, 5-9.

Junthong, N. Netpradit, S. \& Boonlue, S. (2018). Design and Development of Teaching Tools in Dimensional Geometry for Visually Impaired Students Using Object Models 
from 3D Printing. Proceedings of $10^{\text {th }}$ International Conference on Languages, Humanities, Education and Social Sciences (LHESS-18), Kyoto (Japan), April 19-20, 2018, 78-84. Loconsole, C. Leonardis, D. Bergamasco, M. \& Frisoli, A. (2016). An Experimental Study on Fused-Deposition-Modeling Technology as an Alternative Method for Low-Cost Braille Printing. Proceedings of the AHFE 2016 International Conference on Design for Inclusion, Florida (USA), July 27-31, 2016, 201-211. DOI: 10.1007/978-3-319-41962-6_18.

Mudaly, V. \& Sibiya, M. (2018). The effects of the Geoboard on learner understanding of geometric theorems. International Journal of Sciences and Research, 74, 90-98. DOI: 10.21506/j.ponte.2018.11.8.

Teachnology. (2019). What Is Geometry? When Do You Use It In The Real World?. Teachnology. Retrieved 1/12/2019, from https://www.teach-nology.com/teachers/ subject_matter/math/geometry/

The Institute for the Promotion of Teaching Science and Technology (IPST), Ministry of Education. (2008). Nangsữ rīan rāiwichā phữnthān khanittasāt chan prathomsưksā pī thī sì (Phim khrang thī 10) [Textbook mathematics for Grade 4 (10 ${ }^{\text {th }}$ ed.)]. (32-57, 116, 146-156). Bangkok: Office of the Welfare Promotion Commission for Teachers and Education Personnel.

Tractus3D. (2019). Learn more about the advantages of 3D printing. Tractus3D. Retrieved 1/12/2019, from https://tractus3d.com/what-is-3d-printing/advantages-of-3d-printing/ Zahra, A. Budayasa, I. \& Juniati, D (2018). The blind student's interpretation of two-dimensional shapes in geometry. Journal of Physics, Conf. Series 947, 1-6. DOI:10.1088/1742$6596 / 947 / 1 / 012055$. 